\title{
Biocompatibility and anticancer activity of $L$-phenyl alanine-coated iron oxide magnetic nanoparticles as potential chrysin delivery system-CORRIGENDUM
}

\author{
Hamed Nosrati, Elham Javani, Marziyeh Salehiabar, Hamidreza Kheiri Manjili, \\ Soodabeh Davaran, Hossein Danafar
}

doi: 10.1557/jmr.2018.148 Published online by Cambridge University Press: 12 June 2018.

In Fig. 3 of this article [1], a human error occurred during the DLS experiment. The human error involved mislabeling of samples during transfer of results.

The replacement of this valid data does not influence the main conclusions of the paper. In order to present valid results, DLS experiments were carried out again.

Figure 3 is therefore replaced below with corrected data.
The authors apologize for this error.

\section{References}

1. H. Nosrati, E. Javani, M. Salehiabar, H. Kheiri Manjili,

S. Davaran, and H. Danafar: J. Mater. Res. 33, 1602 (2018).

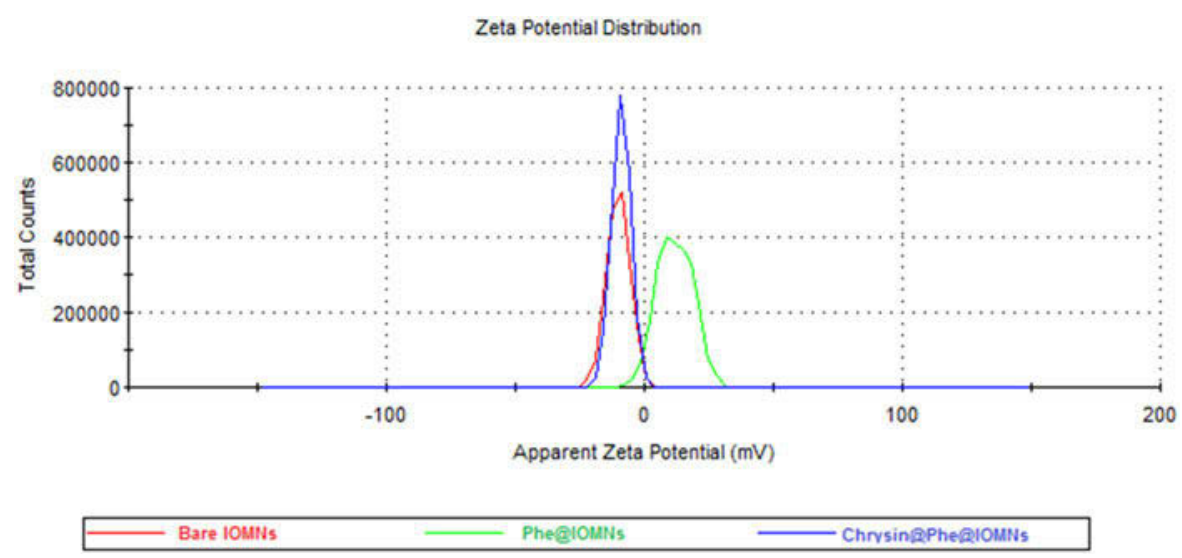

Figure 3. 